Volume 3, Issue 1, February 2018, Pages: 238, DOI: http://dx.doi.org/10.19082/ah238

\title{
STUDY OF SOME RISK FACTORS ASSOCIATED WITH TYPE 2 DIABETES IN THE GHAZAOUET REGION, WILAYA OF TLEMCEN (WEST ALGERIA)
}

\author{
Sarra Khater ${ }^{1,2}$, Haouari Hamdaoui ${ }^{1,2}$, Zakarya Moqaddem ${ }^{1,2}$, Nafissa Chabni ${ }^{3}$, Djamel Belkhatir ${ }^{1}$, Majda Dali1, \\ Amaria Aouar ${ }^{1}$
}

1: Laboratory for the valorisation of human actions for environmental protection and application in public health Department of Biology, Faculty of Science, Abou-Bekr University Belkaid, Tlemcen

2: Cancer Lab, Faculty of Medicine, Abou-Bekr Belkaid University, Tlemcen

3: Service for epidemiology, University Hospital of Tlemcen

sarra1112@yahoo.fr

\section{TYPE OF ARTICLE: CONFERENCE ABSTRACT}

\begin{abstract}
Background: Type 2 diabetes now has the dimensions of a pandemic, and in Algeria, diabetes is a serious public health problem. More than 1.4 million adults (6.95\%) of the adult population suffer from it. This study analyzes type 2 diabetes in relation to some risk factors in the Ghazaouet region (west Algeria), showing the impact of inbreeding, heredity, certain socio-demographics, clinical and biological factors on the frequency of this disease.

Methods: This is a cross-sectional, descriptive, case-control study of a population of 161 people, including 69 diabetics and 92 controls, at the PH (Public Hospital) in Ghazaouet. The data were analyzed by a logistic regression, processed by the Minitab version 16 .

Results: In this population, type 2 diabetes is statistically associated with age, sex, family history of diabetes, consanguinity and hypertension $(\mathrm{p}<5 \%)$. The variables used by the logistic regression model as risk factors for diabetes in this region are age, family history of diabetes, and high blood pressure.

Conclusion: Type 2 diabetes in this region is largely related to hereditary factors and high blood pressure. A better understanding of these factors is essential for the establishment of effective prevention policies.
\end{abstract}

KEYWORDS: Diabetes type 2, Risk factors, Public health, Population of Ghazaouet, West Algeria.

\footnotetext{
Abstracts of Second International Conference on Health Sciences and Medical Technologies, 10-12 October 2017, Tlemcen, Algeria (ICHSMT-17)

(C) 2018 The Authors. This is an open access article under the terms of the Creative Commons Attribution-NonCommercialNoDerivs License, which permits use and distribution in any medium, provided the original work is properly cited, the use is non-commercial and no modifications or adaptations are made.
} 